\title{
Selected fracture criteria of elastic-plastic materials
}

\author{
O kryteriach pękania materiałów sprężysto-plastycznych
}

MARCIN GRABA *

DOI: https://doi.org/10.17814/mechanik.2017.12.201

\begin{abstract}
The paper presents a brief overview of selected fracture criteria of elastic-plastic materials. These criteria, ones of many, can be used to assess the real fracture toughness of different construction materials, provided the user has the required parameters defined by the fracture mechanics.
\end{abstract}

KEYWORDS: fracture criteria, geometric constraints, J-integral, fracture toughness

The use of elastic-plastic fracture mechanics in engineering analysis is not limited to assessing the distribution of stress and strain fields in front of the crack tip. At present, fracture mechanics also includes: assessment of the level of effort of a structure containing defects (assessment of limit loads, limit load capacity), analysis using appropriate destruction diagrams or assessment of the actual fracture toughness of structural elements with defects [1-3]. While the assessment of the load carrying capacity (relative limit loads) and analysis according to the appropriate destruction diagrams (in the basic approach) [1] do not require knowledge of too many parameters of fracture mechanics characterizing the material of the structural element, it applies to selected fracture criteria in addition to knowledge of basic material constants (yield stress $\sigma_{0}$, Young's modulus $E$ or exponent of the strengthening of $n$ in Ramberg-Osgood relationship), it is necessary to know the parameters of the HRR field [4, 5] and selected measures of geometrical constraints, defined in the works $[6,7]$.

Among measures of geometrical constraints (i.e. constraints dependent on the geometry and material constants - which construction material puts plastic deformations developing under the influence of external load [6, 7]), one can distinguish: $Q$ stress [8], stress triaxiality parameter $T_{z}$ [9], mean stresses $\sigma_{m}$ normalized by the yield stress or through effective stress $\left(\sigma_{m} / \sigma_{0}\right.$ or $\sigma_{m} / \sigma_{\text {eff }}$ respectively) [10]. Parameters of geometrical constraints include also parameters $Q^{*}$ and $Q^{*}[11,12]$ and the $T_{m}$ parameter discussed in the above-mentioned works, i.e. the coefficient of triaxiality of stress $T_{z}$ averaged over the thickness of the specimen (structural element) [14]. The values of $Q^{*}{ }_{m}$ and $T_{m}$, determined as averaged values over the specimen thickness, have already been used to describe the stress fields in front of the crack tip in elastic-plastic materials for 3D issues [13], as well as in the fracture criterion proposed in 2012 [15]. This criterion in the most general form can be saved as:

Dr inż. Marcin Graba (mgraba@tu.kielce.pl) - Katedra Technologii Mechanicznej i Metrologii, Wydział Mechatroniki i Budowy Maszyn Politechniki Świętokrzyskiej

$$
\begin{gathered}
J_{\mathrm{C}}=J_{\mathrm{IC}} \cdot \frac{I_{\mathrm{n}}\left(n, T_{\mathrm{m}}\right)}{I_{\mathrm{n}}\left(n, T_{\mathrm{m} \_ \text {ref }}\right)} \cdot \\
\cdot\left[\frac{\widetilde{\sigma}_{i j}\left(\theta, n, T_{\mathrm{m} \text { ref }}\right)}{\widetilde{\sigma}_{i j}\left(\theta, n, T_{\mathrm{m}}\right)} \cdot\left(\frac{\sigma_{\mathrm{c}}-\sigma_{0} \cdot Q_{\mathrm{m}}^{*}\left(n, T_{\mathrm{m}}\right) \delta_{i j}}{\sigma_{\mathrm{c}}-\sigma_{0} \cdot Q_{\mathrm{m} \_ \text {ref }}^{*}\left(n, T_{\mathrm{m} \text { ref }}\right) \delta_{i j}}\right)\right]^{1+n}
\end{gathered}
$$

where:

$J_{C}$ - actual fracture toughness (expressed using the $\mathrm{J}$ integral [16]);

$J_{I C}$ - critical value of the J-integral, determined experimentally according to the standard [16] for a specimen dominated by a plane strain (in many Eqs. Denoted as "p.s.o.");

$I_{n}\left(n, T_{\mathrm{m}}\right), I_{n}\left(n, T_{\mathrm{m} \_ \text {ref }}\right), \widetilde{\sigma_{l j}}\left(\theta, n, T_{\mathrm{m}}\right), \widetilde{\sigma_{l j}}\left(\theta, n, T_{\mathrm{m} \_ \text {ref }}\right) \quad$ functions that can be determined on the basis of literature data or using the computer program presented in [17] for the $T_{m}$ parameter value (characterizing the triaxiality level of stress for the analyzed element) or $T_{m}$ ref parameter (characterizing the triaxiality level of stresses for the specimen, for which $J_{I C}$ has been determined);

$\theta$ - coordinate in the polar coordinate system $(r, \theta, z)$, hooked at the tip of the crack in the axis of the specimen (structural element);

$Q^{*}{ }_{m i}$ and $Q_{m \text { ref }}$ - averaged over the thickness of the $Q^{*}[11$ 13] parameter value, for the considered structural component for which $J_{C}$ fracture toughness is sought, and the specimen for which the $J_{I C}$ value was determined experimentally $\left(Q^{*}{ }_{m}\right.$ and $Q_{m \_}$ref parameters depend on the strain hardening exponent $n$ and the value of the parameter $T_{m}$ );

$\sigma_{c}$ - critical stresses, which can be determined for a given material on the basis of laboratory experiments and numerical calculations, or can be found in the literature [18];

$\delta_{i j}-$ Kronecker delta.

Fracture criterium of elastic-plastic materials (1) have been discussed in detail in [15], where it was verified using commonly accepted experimental results presented in [19]. It is worth noting that the criterion presented in [15] is true for three-dimensional structural elements, while the criteria presented in $[8,18]$ relate to a plane strain state.

Based on the method of determining the fracture criterion described in [15], analogous approaches can be proposed using other parameters of geometrical constraints, such as:

- quotient of normal average stresses $\sigma_{m}$ and yield point (yield stress) $\sigma_{0}$ :

$$
\frac{\sigma_{\mathrm{m}}}{\sigma_{0}}=\frac{1}{\sigma_{0}} \cdot \frac{\left(\sigma_{11}+\sigma_{22}+\sigma_{33}\right)}{3}
$$


where: $\sigma_{11}, \sigma_{22}, \sigma_{33}$ - normal components of stress tensor;

- quotient of normal mean stresses $\sigma_{m}$ and effective stresses $\sigma_{\text {eff }}$ according to the $\mathrm{HMH}$ hypothesis $-\sigma_{m} / \sigma_{\text {eff }}$;

- $Q^{\text {oso }}$ parameter being the normalized by the yield point difference between the actual stress distribution $\sigma_{22}$ MES and the distribution estimated for the plane strain $\sigma_{22 \_p s o}$ :

$$
Q^{\text {pso }}=\frac{\sigma_{22 \_ \text {MES }}-\sigma_{22 \_ \text {pso }}}{\sigma_{0}}
$$

where:

$$
\sigma_{i j \_ \text {pso }}=\sigma_{0} \cdot\left(\frac{J}{\alpha \cdot \sigma_{0} \cdot \epsilon_{0} \cdot I_{n}(n, \mathrm{pso}) \cdot r}\right)^{\frac{1}{1+n}} \cdot \widetilde{\sigma_{l \jmath}}(\theta, n, \mathrm{pso})
$$

whereby: $I_{n}(n, \mathrm{pso}), \widetilde{\sigma_{l j}}(\theta, n, \mathrm{pso})$ - functions determined according to the algorithm presented in $[13,17]$ assuming the domination of the plane strain state.

These parameters should always be determined for three-dimensional structural objects (specimens) in order to include both in-plane and out-of-plane constraints in the proposed fracture criteria [6, 7]. Next, proposals for new fracture criteria for elastic-plastic materials together with the assessment of the impact of various parameters of fracture mechanics are discussed.

\section{A two-parameter fracture criterion $J=J\left(U_{\mathrm{IC}}, Q_{\mathrm{m}}^{\mathrm{pso}}\right)$}

As already mentioned, one of the measures of geometric constraints is the $Q^{\text {pso }}$ parameter. Some researchers [20, 21] proposed the expression of this parameter using the $Q$ stress formula, defined by O'Dowd [8], as the amount correcting the stress distribution obtained on the basis of the HRR solution [5, 6]. This parameter should be counted at each point in front of the crack tip, along its entire front. An alternative formula for the stress distribution before the crack tip for elasticplastic materials in the case of 3D issues has the form:

$$
\begin{gathered}
\sigma_{i j}=\sigma_{0} \cdot\left(\frac{J}{\alpha \cdot \sigma_{0} \cdot \epsilon_{0} \cdot I_{n}(n, \mathrm{pso}) \cdot r}\right)^{\frac{1}{1+n}} \\
\cdot \widetilde{\sigma_{l j}}(\theta, n, \mathrm{pso})+Q^{\mathrm{pso}} \cdot \sigma_{0} \cdot \delta_{i j}
\end{gathered}
$$

It is proposed that the $Q^{\text {pso }}$ parameter should be determined for the direction $\theta=0$ and the distance $r=$ $2 \mathrm{~J} / \sigma_{0}$. Formula (5) is true for each point in front of the front of the crack. This description in the case of a structural element of a specified thickness and resistance to cracking takes the form:

$$
\begin{gathered}
\sigma_{i j}=\sigma_{0} \cdot\left(\frac{J}{\alpha \cdot \sigma_{0} \cdot \epsilon_{0} \cdot I_{n}(n, \mathrm{pso}) \cdot r}\right)^{\frac{1}{1+n}} \cdot \widetilde{\sigma_{l j}}(\theta, n, \mathrm{pso}) \\
+Q_{\mathrm{av}}^{\mathrm{pso}} \cdot \sigma_{0} \cdot \delta_{i j}
\end{gathered}
$$

where: $Q_{\mathrm{av}}^{\mathrm{pso}}$ - the value of the $Q^{\text {pso }}$ parameter, averaged over the thickness.

When formulating the criteria for cracking elastic-plastic materials that are characterized by a brittle fracture mechanism, it is assumed that the cracking process takes place when the crack opening stress reaches the critical value $\sigma_{c}$ at a specified critical distance from the crack tip, denoted by $r_{c}[15,19,22]$. This type of analysis is presented in detail in $[15,19,22]$. Using the analysis method presented in [15], an alternative to [15] crack criterion can be given by analogy, based on the $Q^{\text {pso }}$ av parameter:

$$
J_{\mathrm{C}}=J_{\mathrm{IC}} \cdot\left[\frac{\sigma_{\mathrm{c}}-Q_{\mathrm{av}}^{\mathrm{pso}} \cdot \sigma_{0} \cdot \delta_{i j}}{\sigma_{\mathrm{c}}-Q_{\mathrm{av}}^{\mathrm{pso} \text { ref }} \cdot \sigma_{0} \cdot \delta_{i j}}\right]^{n+1}
$$

where: $J_{C}$ - actual sought fracture toughness; $Q_{\mathrm{av}}^{\mathrm{pso}}$ parameter determined for the specimen for which $J_{C}$ is sought (you can use the catalog of ready solutions given in [21]); $Q_{\mathrm{av}}^{\mathrm{pso}_{\text {ref }}}$ - the value of the parameter $Q_{\mathrm{av}}^{\mathrm{pso}{ }_{\text {ref }}}$ determined numerically for the specimen for which the critical value of fracture toughness $J_{I C}$ was determined for the laboratory; $\sigma_{c}$ - critical stress.

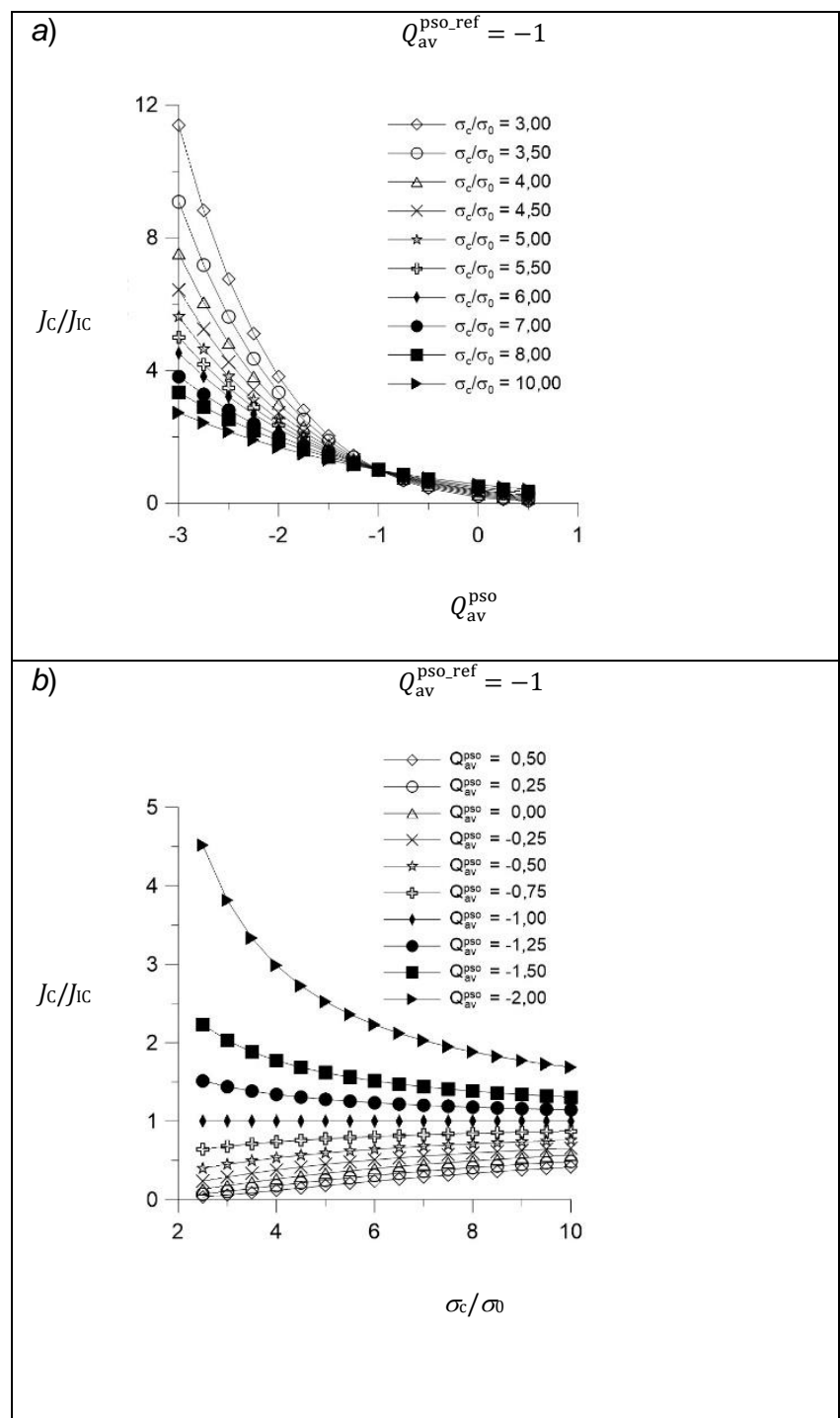

Fig. 1. Effect of: a) parameter $Q_{\mathrm{av}}^{\mathrm{pso}}$ (for different values of critical stresses $\sigma_{d}\left(\sigma_{0}\right)$ to the value of the real fracture toughness; b) critical stresses $\sigma_{d} \sigma_{0}$ (for different values of parameter $Q_{\mathrm{av}}^{\mathrm{pso}}$ ) to the value of the real fracture toughness

Fig. 1 depicts hypothetical changes in the real fracture toughness $J_{C}$ normalized by fracture toughness $J_{I C}$ determined with the assumption of domination of planes train state. The higher the value of critical stresses $\sigma_{c}$, the smaller the value of the real fracture toughness $J_{c}$, determined for the set values of the parameters of ties 
$Q_{\mathrm{av}}^{\text {pso }}$ and $Q_{\mathrm{av}}^{\text {pso }}$. However, it should be noted that at a given level of $Q_{\mathrm{av}}^{\mathrm{pso}}$ and $Q_{\mathrm{av}}^{\text {pso ref }}$ parameters, this trend is slightly reversed. The higher the value of parameter $Q_{\mathrm{av}}^{\mathrm{pso}}$ the lower the real fracture toughness $J_{c}$. It can be concluded that the higher the level of constraints (the more negative the $Q_{\mathrm{av}}^{\mathrm{pso}}$ parameter), the higher the real fracture toughness $J_{C}$.

\section{A two-parameter fracture criterion $\boldsymbol{J}=\boldsymbol{J}\left(\boldsymbol{U}_{\mathrm{IC}}, \sigma_{\mathrm{m}} / \sigma_{0}\right)$}

In 1995, O'Dowd [8], summing up the previous considerations regarding $Q$ stress, suggested that they should be determined not only taking into account the stress opening the crack surfaces, but as a parameter dependent on the mean stresses $\sigma_{m}$ :

$$
Q_{\mathrm{m}}=\frac{\sigma_{\mathrm{m} \_\mathrm{MES}}-\sigma_{\mathrm{m} \_\mathrm{pso}}}{\sigma_{0}} \mathrm{dla} \theta=0 \mathrm{i} r=2 J / \sigma_{0}
$$

where subscript „MES” denotes that stress components were calculated using Finite Element Method, but subscript „pso” denotes, the stress components where calculated using HRR solution for plane strain state.

If, therefore, the $Q$ stress in the fracture criterion proposed by O'Dowd [8] is replaced by the parameter $Q_{m}$, it can be written in a new form:

$$
J_{\mathrm{C}}=J_{\mathrm{IC}} \cdot\left[1-\frac{Q_{\mathrm{m}} \cdot \sigma_{0}}{\sigma_{\mathrm{c}}}\right]^{n+1}
$$

Development of equation (9) leads to the following form of fracture criterion:

$$
J_{\mathrm{C}}=J_{\mathrm{IC}} \cdot\left[1-\frac{\sigma_{0}}{\sigma_{\mathrm{c}}} \cdot\left(\frac{\sigma_{\mathrm{m}}}{\sigma_{0}}-\frac{\sigma_{\mathrm{m} \_ \text {pso }}}{\sigma_{0}}\right)\right]^{n+1}
$$

Formula (10) can be used when the critical value of $J_{I C}$ fracture toughness is determined in the laboratory for a specimen dominated by plane strain state, for which the crack length according to the recommendations of the standard is $a / W=0.5$, and the value of parameter $Q_{m}=0$.

However, under real laboratory conditions, although the crack length is $a / W=0.5$, the materials of such specimens are extremely rarely characterized by a bond level of zero. This fact should be taken into account in the fracture criterion, introducing an appropriate reference condition.

Based on these considerations, a new form of the fracture criterion (10) can be written by analogy, in which the reference state will be characterized by the value of parameter $Q_{m} \neq 0$.

$$
J_{\mathrm{C}}=J_{\mathrm{IC}} \cdot\left[\frac{\sigma_{\mathrm{c}}-\sigma_{0} \cdot\left(\frac{\sigma_{\mathrm{m}}}{\sigma_{0}}-\frac{\sigma_{\mathrm{m} \_ \text {pso }}}{\sigma_{0}}\right)}{\sigma_{\mathrm{c}}-\sigma_{0} \cdot\left(\frac{\sigma_{\mathrm{m} \_ \text {ref }}}{\sigma_{0}}-\frac{\sigma_{\mathrm{m} \_ \text {pso }}}{\sigma_{0}}\right)}\right]^{n+1}
$$

The results presented in [21] in the form of changes in the parameter value $\sigma_{m} / \sigma_{0}$ may facilitate the use of fracture criteria (10) and (11). Fig. 2 presents the influence of various parameters on the real fracture toughness $J_{C}$, which were used in the criterion proposal (11). The greater the level of average stress $\sigma_{m} / \sigma_{0}$, the smaller the value of the real fracture toughness $J_{c}$, which also decreases with the increase of the level of critical stress $\sigma_{c}$.

a)

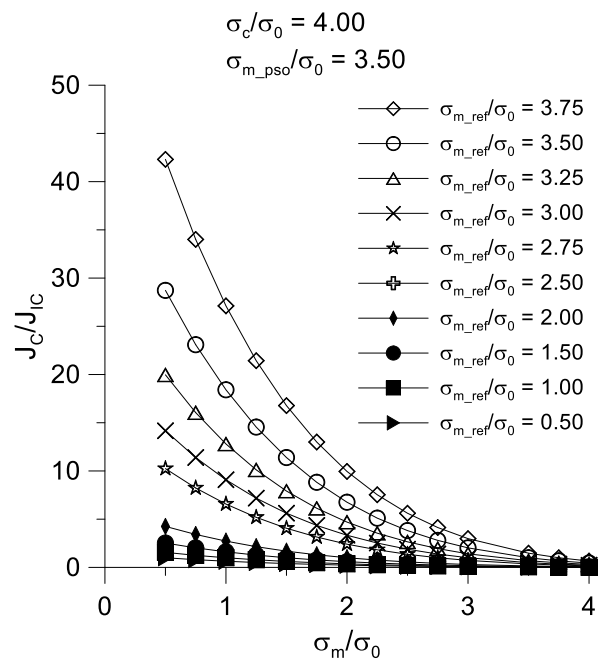

b)

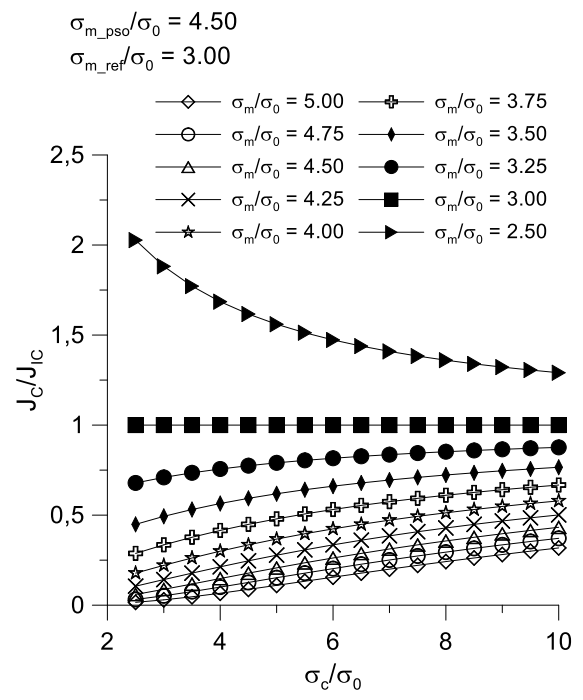

Fig. 2. Influence of the selected parameters in the formula (11) on the real fracture toughness: a) the effect of the quotient $\sigma_{m} / \sigma_{0}$ for the determined values of $\sigma_{m}$ pso $/ \sigma_{0}$ and $\sigma_{d} / \sigma_{0}$; b) the impact of the quotient $\sigma_{d} / \sigma_{0}$ for the set values $\sigma_{m \_p s d} / \sigma_{0}$ and $\sigma_{m \_r e} / \sigma_{0}$

\section{A two-parameter fracture criterion $\boldsymbol{J}=\boldsymbol{J}\left(\boldsymbol{U}_{\mathrm{IC}}, \sigma_{\mathrm{m}} / \sigma_{\mathrm{eff}}\right)$}

In 1995 Guo Wanlin [14] presented the following fracture criterion:

$$
J_{\mathrm{C}} \cdot F\left(\frac{\sigma_{\mathrm{m}}}{\sigma_{\mathrm{eff}}}\right)=\mathrm{const}
$$

but, in the form of $F\left(\frac{\sigma_{\mathrm{m}}}{\sigma_{\mathrm{eff}}}\right)$ function, the influence of out-ofplanes constraints (the constraints in the thickness direction) is taken into account by means of the triaxiality coefficient of stresses:

$$
F\left(\frac{\sigma_{\mathrm{m}}}{\sigma_{\mathrm{eff}}}\right)=\frac{2}{3}(1+v)+3(1-2 v)\left(\frac{\sigma_{\mathrm{m}}}{\sigma_{\mathrm{eff}}}\right)^{2}
$$


a)

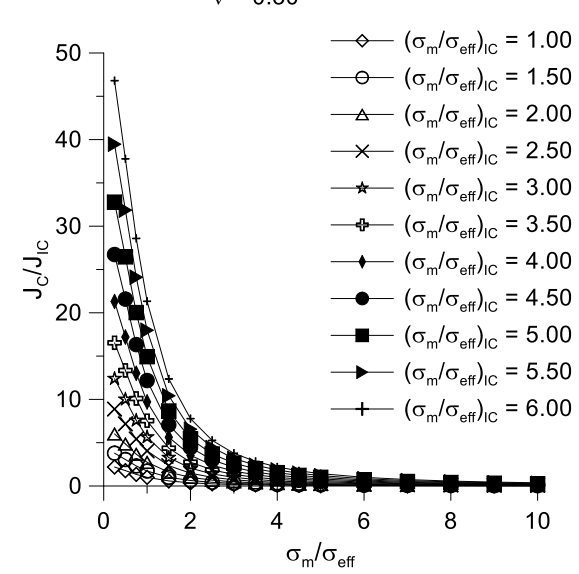

b)

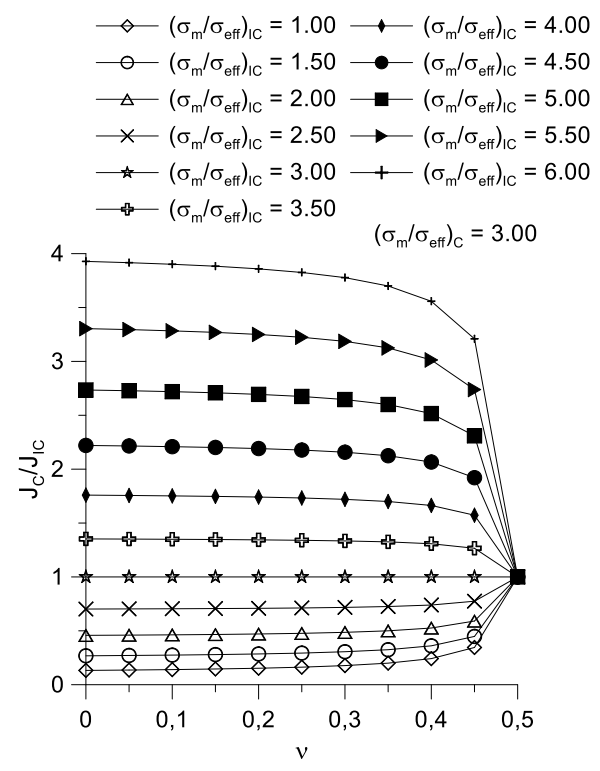

Fig. 3. Influence of the selected parameters in the formula (14) on the real fracture toughness: a) the effect of the quotient $\sigma_{m} / \sigma_{\text {eff }}$ for the determined values $\left(\sigma_{m} / \sigma_{\text {eff }} / c ; b\right)$ the effect of Poisson's coefficient on set values $\left(\sigma_{m} / \sigma_{\text {eff }}\right)_{I C}$

Based on the formula (12), one can postulate that the real fracture toughness $J_{C}$ be calculated as:

$$
J_{\mathrm{C}}=J_{\mathrm{IC}} \cdot\left[\frac{\frac{2}{3}(1+v)+3(1-2 v)\left(\frac{\sigma_{\mathrm{m}}}{\sigma_{\mathrm{eff}}}\right)_{\mathrm{IC}}^{2}}{\frac{2}{3}(1+v)+3(1-2 v)\left(\frac{\sigma_{\mathrm{m}}}{\sigma_{\mathrm{eff}}}\right)_{\mathrm{C}}^{2}}\right]
$$

where the subscripts mean: $I C$ - that the value of the $\mathrm{J}$ integral or the quotient $\sigma_{\mathrm{m}} / \sigma_{\text {eff }}$ was determined for the spcimen for which the critical fracture toughness $J_{I C}$ was determined according to the ASTM standard; $C$ - that the value of the $\mathrm{J}$-integral or the quotient $\sigma_{m} / \sigma_{\text {eff }}$ refers to the specimen for which the real fracture toughness $J_{C}$ is sought.

Numerical calculation results given in [21] in the form of changes in the parameter value $\sigma_{m} / \sigma_{\text {eff }}$ may facilitate the use of the fracture criterion (14). Fig. 3 shows the influence of selected parameters on the value of the real fracture toughness. The higher the value of the quotient $\sigma_{m} / \sigma_{\text {eff, }}$ the smaller the value of the real fracture toughness $J_{C}$, which decreases with the increase of the Poisson coefficient, if the quotient $\sigma_{m} / \sigma_{\text {eff }}<3$.

\section{A two-parameter fracture criterion $J=J\left(U_{I C}, d_{n}\right)$}

The fracture criterion proposals presented above are suitable for materials characterized by a brittle fracture mechanism, when the cracking process begins after the stress has reached the critical value $\sigma_{c}$ at a critical distance from the cracks apex $r_{c}$. In the case of considerations regarding the process of cracking of ductile materials, the crack tip opening displacement is a convenient parameter [7]. In 1995, O'Dowd [8] mentioned the fracture criterion based on this particular fracture parameter. He assumed that the cracking process would occur if the crack tip opening displacement reached the critical value $\delta_{c}$. In 1981, Shih connected the crack tip opening displacement $\delta_{T}$ with the $\mathrm{J}$ integral value:

$$
\delta_{\mathrm{T}}=d_{\mathrm{n}} \cdot J
$$

where: $d_{n}$ - coefficient determined for a given yield point quotient $\sigma_{0} / E$, strain hardening exponent $\mathrm{n}$, and also for plane stress ar plane strain.

The $d_{n}$ coefficient is determined when determining the parameters of the function with the tilde " ", while solving the differential equation of the fourth degree as part of the analysis of the HRR problem. This function can be estimated using the computer program indicated in the works $[13,17]$. Guo Wanlin [14], the value of the $d_{n}$ function additionally depended on the triaxiality coefficient of stress denoted as $T_{z}$ - the aforementioned program determines the value of the $d_{n}$ coefficient also for such an approach. Fig. 4 presents changes in the value of the $d_{n}$ coefficient in the function of the yield point quotient and Young's modulus for the four values of the Ramberg-Osgood's exponent in the case of plane strain state domination [24].

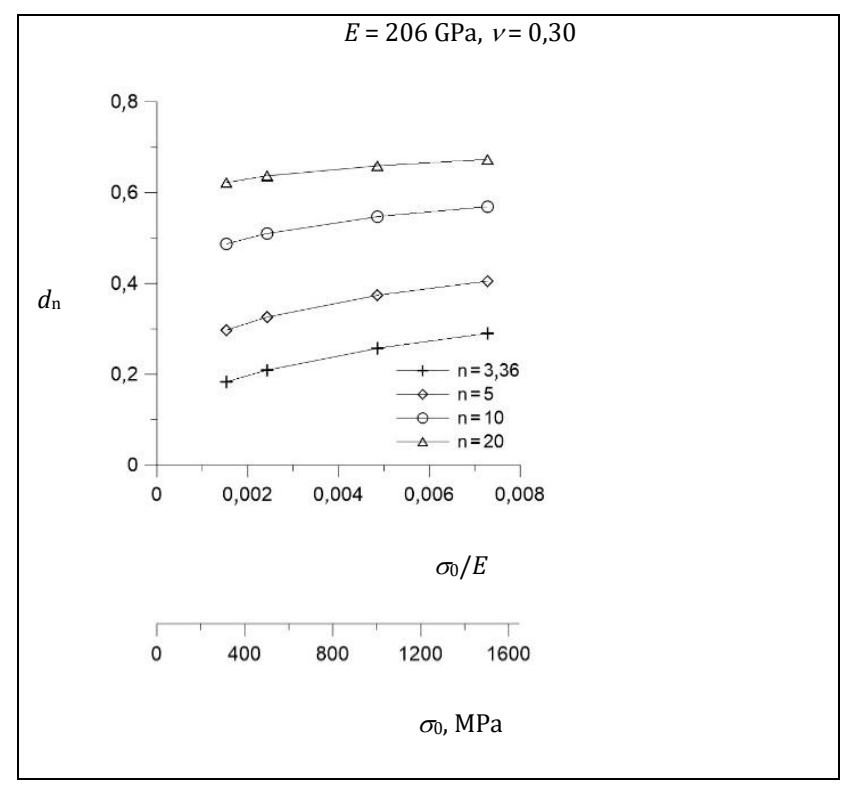

Fig. 4. Values of $d_{n}$ coefficient (15) for various strain hardening exponents and yield stress [24]

The numerical tests carried out indicate, however, that the value of the $d_{n}$ coefficient depends not only on the material, but also on the geometry of the specimen (fig. 5a). In work [24] the dependence of the $d_{n}$ coefficient on the $Q$ stress in the case of the $\operatorname{SEN}(B)$ beam dominated by plane strain. is proved, as well as the dependence of this coefficient on the level of external load [24]. As it can be seen, after exceeding a certain level of external load, the value of $d_{n}$ coefficient reaches the saturation level and does not change with the increasing external load (fig. 5b) [24]. 
For the case of plane strain, O'Dowd's proposed cracking hypothesis for a normative specimen with a relative crack length of $a / W=0.5$ can be represented as:

$$
\delta_{\mathrm{c}}=d_{\mathrm{n}}^{\mathrm{IC}}\left(n, \sigma_{0} / E, a / W\right) \cdot J_{\mathrm{IC}}
$$

In turn, for any specimen that does not meet the normative requirements, but made of the same material, it can be written that:

$$
\delta_{\mathrm{c}}=d_{\mathrm{n}}^{\mathrm{C}}\left(n, \sigma_{0} / E, a / W\right) \cdot J_{\mathrm{C}}
$$

The combination of both models leads to the formulation of the fracture criterion in the form of:

$$
J_{\mathrm{C}}=J_{\mathrm{IC}} \cdot \frac{d_{\mathrm{n}}^{\mathrm{IC}}\left(n, \sigma_{0} / E, a / W\right)}{d_{\mathrm{n}}^{\mathrm{C}}\left(n, \sigma_{0} / E, a / W\right)}
$$

where: $d_{\mathrm{n}}^{\mathrm{IC}}$ - value of $d_{n}$ coefficient for the specimen for which critical fracture toughness $J_{I C}$ which was determined in laboratory conditions; $d_{\mathrm{n}}^{\mathrm{C}}$ - value of $d_{n}$ coefficient for the specimen for which the real fracture toughness $J_{C}$ is sought.

The use of the fracture criterion (18) first of all requires knowledge of fracture toughness determined for planes train state - $J_{I C}$, but also values of $d_{\mathrm{n}}^{\mathrm{IC}}$ and $d_{\mathrm{n}}^{\mathrm{C}} \ln$ [24], values of the $d_{\mathrm{n}}=f\left(n, \sigma_{0} / E, a / W\right)$, coefficient were estimated based on numerical calculations, and the obtained results were approximated to facilitate possible engineering analyzes.

The formula (19) allows to estimate the value of the $d_{n}$ coefficient provided that the characteristics of the material are known (yield point $\sigma_{0}$, strain hardening exponent $n$ ) and the relative crack length $a / W$ [24]:

$$
d_{\mathrm{n}}\left(n, \sigma_{0} / E, a / W\right)=a_{1}+b_{1} \cdot \ln \left(\sigma_{0} / E\right)+c_{1} \cdot(n)^{d_{1}}
$$

where: $a_{1}, b_{1}, c_{1}$ and $d_{1}$ - coefficients that are functions of the relative crack length $a / W$, which can be estimated as [24]:

$$
\begin{aligned}
& a_{1}(a / W)=-5,6957 \cdot(a / W)^{3}+8,551 \cdot(a / W)^{2}+ \\
& -4,241 \cdot(a / W)+1,5734 \\
& b_{1}(a / W)=0,011 \cdot(a / W)^{3}+0,0191 \cdot(a / W)^{2}+ \\
& -0,0508 \cdot(a / W)+0,0652 \\
& c_{1}(a / W)=-8,2892 \cdot(a / W)^{3}+10,394 \cdot(a / W)^{2}+ \\
& -3,2233 \cdot(a / W)-1,242 \quad \\
& \begin{cases}d_{1}(a / W)=-3,3333 \cdot(a / W)+ \\
-0,3333 & \text { dla } a / W=\langle 0,05 ; 0,20\rangle \\
d_{1}(a / W)=-1 & \text { dla } a / W=\langle 0,20 ; 0,70\rangle\end{cases}
\end{aligned}
$$

Presented method of analysis is not, in principle, either revealing or new, but sometimes when assessing fracture toughness, the fracture criterion given in 1995 by O'Dowd is omitted [8], mainly due to the difficulty in determining various parameters. The criterion is very obvious and easy to apply if values of the $d_{n}$ coefficient, are known [24]. The use of criterion (18) leads to obtaining safe results (which O'Dowd mentioned in 1995). This criterion was developed by the authors of the work [25], in which the method of taking into account geometrical constraints in the case of determining the real fracture toughness was presented.

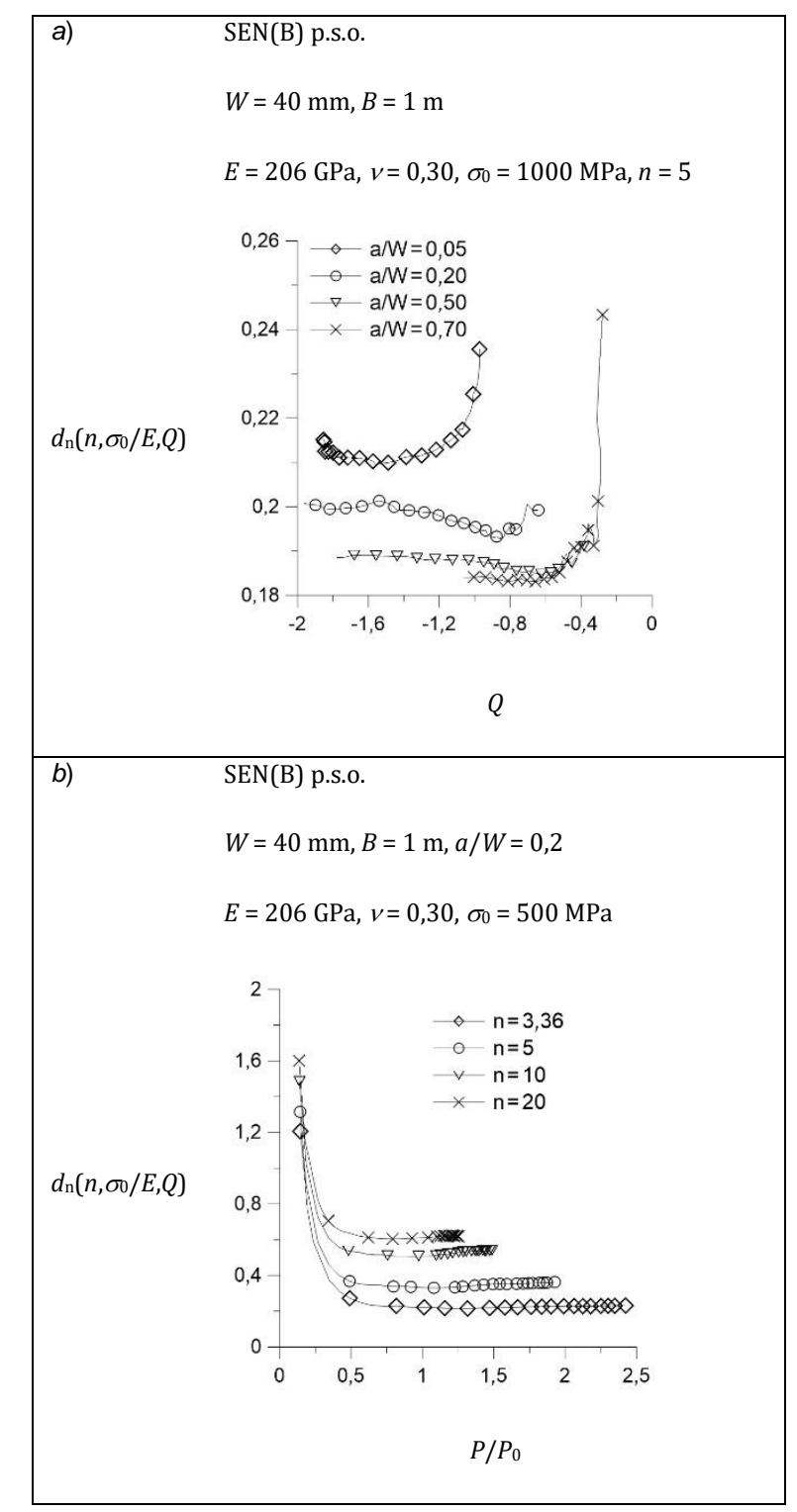

Fig. 5. The effect of: a) the relative crack length $a / W$ on the value of $d_{n}\left(n, \sigma_{0} / E, Q\right)$ as a function of the level of in-plane constraints expressed in $Q$ [24]; b) the exponent $\mathrm{n}$ in the Ramberg-Osgood law on the value of the coefficient $d_{n}\left(n, \sigma_{0} / E, Q\right)$ as a function of the external load $P$ normalized by the limit load $P_{0}$ [24]

\section{Conclusions}

The paper presents a short overview of selected fracture criteria for cracking elastic-plastic materials. Some of the presented models - (1), (12) and (18) - were published in $[15,14,8]$. The remaining ones were created as a result of a trivial analysis based on the O'Dowd's idea from 1995 [8]. It may seem that the fracture criteria presented are simple, but - as shown in [15, 19] uncomplicated solutions can lead to correct, and above all, safe results that are expected in the case of assessing the strength of a structure containing defects.

Based on the presented information, the reader can individually derive the fracture criteria proposed in the work and assess - based on the presented drawings - how the fracture toughness changes with the change of geometrical constraints (expressed by means of various parameters) or reference states.

Although many works have been devoted to the criteria of fracture $[6-8,14,15,18,19,22,25]$, the subject of assessing the actual fracture toughness still remains open, especially in the search for new and above all uncomplicated solutions. 
The work was carried out as part of statutory work with internal number 01.0.09.00/2.01.01.01.0027 MNSP, MKTM.17.002, carried out at the Faculty of Mechatronics and Machine Design at the Kielce University of Technology.

\section{REFERENCES}

1. Kumar V., German M.D., Shih C.F. "An engineering approach for elastic-plastic fracture analysis". Electric Power Research Institute, Inc. Palo Alto, CA 1981, EPRI Report NP-1931.

2. SINTAP: Structural Integrity Assessment Procedures for European Industry. Final Procedure. Brite-Euram Project No. BE951426. Rotherham: British Steel, 1999.

3. FITNET Report (European Fitness-for-service Network). Edited by M. Kocak, S. Webster, J.J. Janosch, R.A. Ainsworth, R. Koers. Contract No. G1RT-CT-2001-05071, 2006.

4. Hutchinson J.W. "Singular behaviour at the end of a tensile crack in a hardening material". Journal of the Mechanics and Physics of Solids. 16 (1968): s.13-31.

5. Rice J.R., Rosengren G.F. "Plane strain deformation near a crack tip in a power-law hardening material". Journal of the Mechanics and Physics of Solids. 16 (1968): s. 1-12.

6. Neimitz A. „Ocena wytrzymałości elementów konstrukcyjnych zawierających pęknięcia (podstawowe elementy procedur SINTAP)". Kielce: Wydawnictwo Politechniki Świętokrzyskiej, 2004.

7. Neimitz A., Dzioba I., Graba M., Okrajni J. „Ocena wytrzymałości, trwałości i bezpieczeństwa pracy elementów konstrukcyjnych zawierających defekty". Podręcznik akademicki. Kielce: Wydawnictwo Politechniki Świętokrzyskiej, 2008.

8. O'Dowd N.P. "Application of two-parameter approaches in elastic-plastic fracture mechanics". Engineering Fracture Mechanics. 52, 3 (1995): s. 445-465.

9. Guo W. "Elastoplastic three dimensional crack border field - I. Singular structure of the field". Engineering Fracture Mechanics. 46, 1 (1993): 93-104.

10. Henry B.S., Luxmoore A.R. "The stress triaxiality constraint and the q-value as a ductile fracture parameter". Engineering Fracture Mechanics. 57, 4 (1997): s. 375-390.

11. Neimitz A., Graba M. "Analytical-numerical hybrid method to determine the stress field in front of the crack in 3D elastic-plastic structural elements". Materiały XVII ECF. Brno (Czechy), wrzesień 2008 r., s. 85.

12. Neimitz A., Graba M. "In and out-of-plane constraint measures. Uniform description". Materiały ICF 12 - 12th International Conference on Fracture, Ottawa (Kanada), 12-17 lipca 2009 r.

13. Graba M. "Numerical analysis of the mechanical fields near the crack tip in the elastic-plastic materials. 3D problems". $\mathrm{PhD}$ dissertation. Kielce: Kielce University of Technology, Faculty of Mechatronics and Machine Building, 2009.

14. Guo Wanlin. "Elastoplastic three dimensional crack border field - III. Fracture parameters". Engineering Fracture Mechanics. 51, 1 (1995): s. 51-71.

15. Graba M. „Propozycja trójparametrycznego kryterium pękania materiałów kruchych”. Przegląd Mechaniczny. 2 (2012): s. 24-31. 16. ASTM. ASTM E 1820-05 Standard Test Method for Measurement of Fracture Toughness. American Society for Testing and Materials, 2005.

17. Gałkiewicz J., Graba M. "Algorithm for determination $\widetilde{\sigma_{l j}}(n, \theta)$, $\widetilde{\varepsilon_{l j}}(n, \theta), d_{n}(n, \theta)$ and $I_{n}(n)$ functions in Hutchinson-Rice-Rosengren solution and its 3D generalization". Journal of Theoretical and Applied Mechanics. 44, 1 (2006): s. 19-30.

18. Ritchie R.O., Knott J.F., Rice J.R. "On the relationship between critical tensile stress and fracture toughness in mild steel". Journal of the Mechanics and Physics of Solids. 21 (1973): s. 395-410.
19. Neimitz A., Dzioba I., Molasy R., Graba M. „Wpływ więzów na odporność na pękanie materiałów kruchych". Materiały XX Sympozjum Zmęczenia i Mechaniki Pękania. Bydgoszcz-Pieczyska, 27-30 kwietnia 2004 r., s. 265-272.

20. Chao Y.J., Zhu X.K., Kim Y., Lar P.S., Pechersky M.J., Morgan M.J. "Characterization of crack-tip field and constraint for bending specimens under large-scale yielding". International Journal of Fracture. 127 (2004): s. 283-302.

21. Raport merytoryczny przygotowany $w$ ramach projektu badawczego IP2012011872 pt. „Katalog parametrów charakteryzujących więzy geometryczne przed frontem szczeliny w materiałach sprężysto-plastycznych. Numeryczna analiza pól mechanicznych - zagadnienia dwu- i trójwymiarowe". Kielce 2016.

22. Neimitz A., Graba M., Gałkiewicz J. "An alternative formulation of the Ritchie-Knott-Rice local fracture criterion". Engineering Fracture Mechanics. 74 (2007): s. 1308-1322.

23. Shih C.F. "Relationship between the J-integral and the crack opening displacement for stationary and extending cracks". Journal of the Mechanics and Physics of Solids. 29 (1981): s. 305329.

24. Graba M. "Numerical analysis of the influence of in-plane constraints on the crack tip opening displacement for SEN(B) specimens under predominantly plane strain conditions". International Journal of Applied Mechanics and Engineering. 21, 4 (2016): s. 849-866 (https://doi.org/10.1515/ijame-2016-0050).

25. Neimitz A., Gałkiewicz J. "Fracture toughness of structural components: influence of constraint". International Journal of Pressure Vessels and Piping. 83 (2006): s. 42-54. . 